\title{
Experimental investigation results of composite RC beams under cyclic loading
}

\author{
Igor Voskoboynikov ${ }^{1 *}$ \\ ${ }^{1}$ Senior lecturer, Construction technology Department, BSTU, 224017 Moskowskajastr 267 Brest, \\ Belarus
}

\begin{abstract}
This paper presents the results of the study of composite beam elements under the action of cyclic loads. The experimental results demonstrated that with a decrease in the level of applied load, with its frequency unchanged, the "viability" of the experimental composite beams increased (the number of cycles before collapse); under cyclic effects, shear deformations and contact openings are characterized by nonlinear functions.
\end{abstract}

\section{Introduction}

Numerous results of experimental studies of shear resistance of flat reinforced and nonreinforced contact joints are presented in the international literature [1, 2, 3, 4]. In most of these experiments, the contact joints were tested with monotonically increasing load until failure. Studies on the behavior of joints modeling the contact between old and new concrete during the repair or strengthening of structures subjected to cyclic loads are relatively rare.

Experiments simulating the behavior of contact joints are performed mainly on: a) cast-insitu samples with a contact crack preformed before testing; b) samples concreted sequentially and consisting of two contact surfaces simulating the joint between old and new

concrete;

c) samples with two contact surfaces simulating the connection of two precast elements;

d) beam samples strengthened with a monolithic layer, with three-point bending causing indirect shear.

\section{Experimental program}

Five composite beam elements, whose geometric characteristics and reinforcement are shown in Figure 1, acted as prototypes.

The in-situ part of the experimental beams was made of concrete on expansive cement, made by a semi-industrial method with mixing of the initial components in the ratio of portland cement (PC): metakaolin (MK): plaster (PL) - 71:14:15. The following components were used to prepare the concrete mixture: PC - Portland cement CEM I-42,5; MK - metakaolin MK-40; PL - ground calcium sulfate dihydrate stone.

\footnotetext{
${ }^{*}$ Corresponding author: vis_cesar@mail.ru
} 
The main physical and mechanical characteristics of the materials of the experimental beams are given in Table 1.

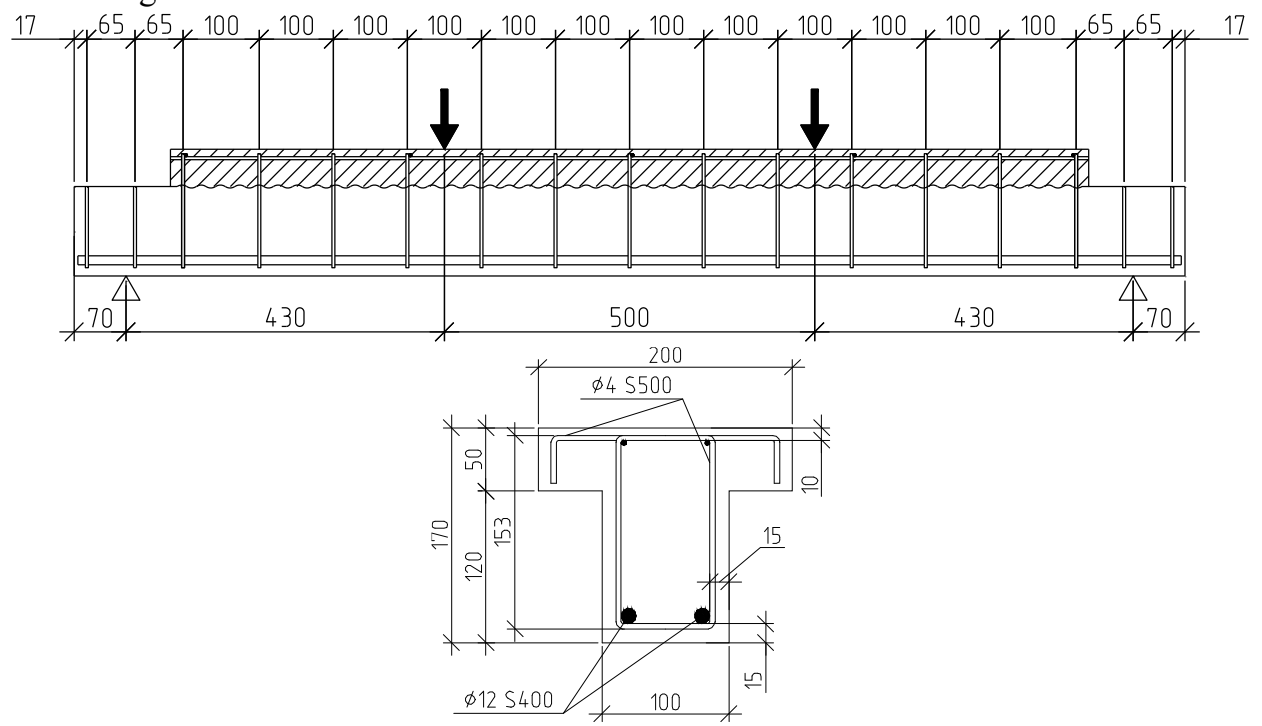

Fig. 1. Geometric characteristics and reinforcement of prototypes

Table 1. Physical and mechanical characteristics of concrete and reinforcement of experimental beams

\begin{tabular}{|c|c|c|c|c|c|}
\hline \multicolumn{5}{|c|}{ Concrete } \\
\hline $\bar{f}_{\text {c,cube }}, \mathrm{MPa}$ & $E_{C}, \mathrm{GPa}$ & $\bar{f}_{c, \text { cube }}, \mathrm{GPa}$ & $E_{C}, \mathrm{GPa}$ & \multicolumn{2}{c|}{ Self-stressing, MPa } \\
\hline 30,98 & 19,98 & \multicolumn{2}{|c|}{65,2} & 31,7 & \multicolumn{2}{c|}{1,91} \\
\hline \multicolumn{6}{|c|}{ Reinforcing steel } \\
\hline Grade & $\begin{array}{c}\text { Diameter } \\
\varnothing, \text { mm }\end{array}$ & $\begin{array}{c}\text { Yield } \\
\text { strength, } \\
\mathrm{MPa}\end{array}$ & $\begin{array}{c}\text { Ultimate strength, } \\
\mathrm{MPa}\end{array}$ & $\begin{array}{c}\text { Modulus of } \\
\text { elasticity } \\
E_{S}, \mathrm{GPa}\end{array}$ & $\begin{array}{c}\text { Percent elongation } \\
\text { at failure, } \%\end{array}$ \\
\hline S500 & 4,0 & 481,0 & 786,0 & 192,3 & 4,5 \\
\hline S500 & 12,0 & 478,0 & 780,0 & 192,8 & 4,6 \\
\hline
\end{tabular}

\section{Test program}

The experimental program provided for testing two beams with static load up to fracture in order to: 1) obtaining the average value of the bearing capacity along the inclined section; 2 ) determining the static failure pattern. The simply supported beams were loaded with two concentrated forces at a distance of $2.5 \mathrm{~d}$ from the supports. The loading stages were 0.1 of the expected ultimate load. At the time of exposure at the stages, the average longitudinal deformations in the middle of the span and along the length of the shear span along the height of the element section, deflections, slippage and the opening width of the contact between the prefabricated and monolithic parts, the crack width were controlled.

The remaining 3 analog beams were tested in a lever reduction gear unit (Figure 2) for cyclic loading. The loading level corresponded to $0.62 \mathrm{Fu}(2$ samples) and $0.9 \mathrm{Fu}$, where $\mathrm{Fu}$ is the average ultimate load according to the results of static tests. 
The main stages of the fabrication of experimental beams are shown in Figure 2.

a)

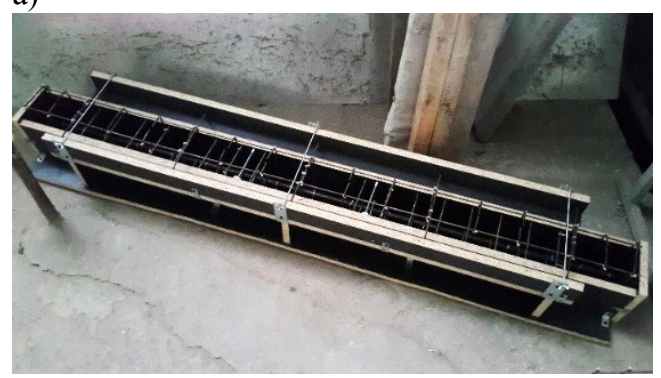

c)

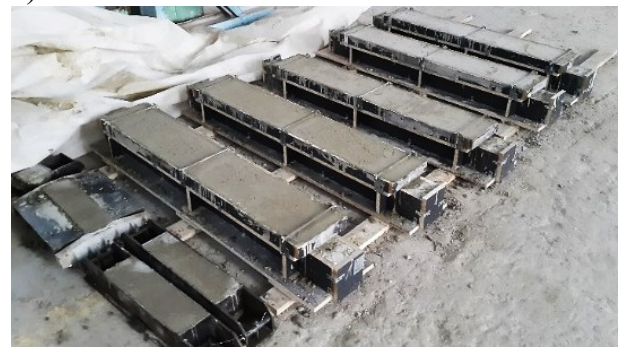

b)

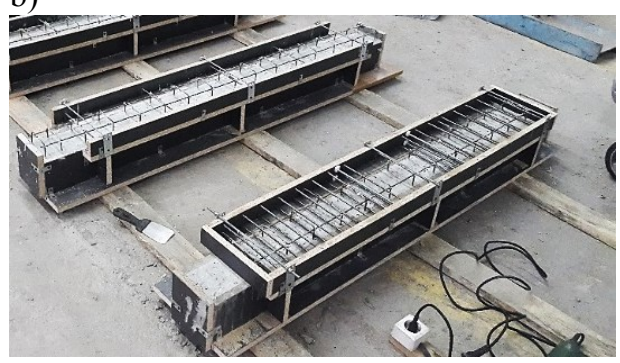

d)

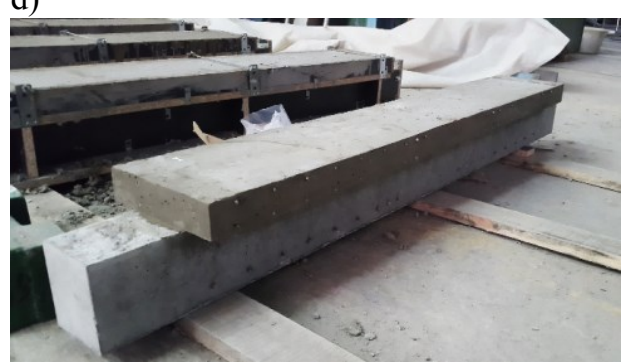

a) formwork with reinforcement frame; b) concreted prefabricated parts;

c) concreting of the cast-in-place part; d) finished beam

Fig. 2. The process of manufacturing experimental beams

Cycle characteristics: frequency - $0.017 \mathrm{~Hz}$ ( 1 cycle per minute), load ratio - 0. Up to the required level, the beams were loaded with a stepped static load. Readings on measuring instruments were taken after 1, 10, 50, 100, 500 cycles (in the loaded and unloaded state) and then every 500 cycles until the moment of failure.

\section{Results of static tests}

The nature of the opening mode cracks, their number, appearance frequency and width are characteristic of the crack pattern in prestressed structures, which in fact are the beams under study.

Opening mode cracks began to form from the second stage of loading, increasing their length and width of opening with each increment of load. The crack- tips did not overcome the contact zone with the monolithic part until the moment of failure of the sample. The opening width stabilized by the 5-6 stage of loading (14.4-17.7 kN) and did not exceed 0.15 $\mathrm{mm}$.

The first cracks inclined to the longitudinal axis of the element appeared at the 6-9 stages (17.7-27.4 kN) approximately in the middle of the prefabricated element with an initial opening width of $0.05-0.1 \mathrm{~mm}$ and developed in both directions.

Approximately the same pattern of formation and development of inclined cracks was observed for all tested beams. From the diagonal cracks that appeared, two main ones were formed, separating the compressed concrete slope. With an increase in the load between these cracks, a horizontal crack of contact disintegration between the prefabricated and monolithic layers of the beam formed, developing further to the point of application of external force. Cracks gradually increased the width up to the limit stage. 
Both beams collapsed along the inclined section from reaching the yield strength of the transverse bars crossing the inclined crack, and a sudden loss of anchoring by the longitudinal main reinforcement (see Table 2).

Table 2. Main results of experimental studies of experimental beams under static load

\begin{tabular}{|c|c|c|c|}
\hline Specimens & $\begin{array}{c}\text { Ultimate } \\
\text { load, } \mathrm{kN}\end{array}$ & $\begin{array}{c}\text { Maximum contact slip, } \\
\mathrm{mm}\end{array}$ & $\begin{array}{c}\text { Maximum deflection in the middle } \\
\text { of the span, } \mathrm{mm}\end{array}$ \\
\hline B1 & 93,85 & 0,225 & 9,775 \\
\hline B5 & 103,73 & 0,245 & 11,69 \\
\hline $\begin{array}{l}\text { Note: the slip was fixed approximately in the middle of the horizontal area of the contact } \\
\text { disintegration between the inclined cracks. The maximum value is presented for the moment } \\
\text { preceding the fracture. }\end{array}$
\end{tabular}

\section{The results of cyclic load tests}

The main test results of experimental beams under cyclic loads are presented in Table 3 .

To achieve a given load level, the test beams were loaded in stages according to the static test method. Therefore, the order of formation and opening of cracks, fixed deformations and deflections did not differ fundamentally from those obtained under static loads.

In the process of repeated loadings, a step-by-step reduction in the length of the anchoring zone of the longitudinal reinforcement was observed in the supporting region cut off by inclined cracks. In the limiting stage, the transverse stirrups broke and the element collapsed.

Thus, it can be concluded that the failure of the beams during cyclic application of the load is caused by the progressive loosening of the concrete structure and the loss of adhesion to the working reinforcement in the supporting area.

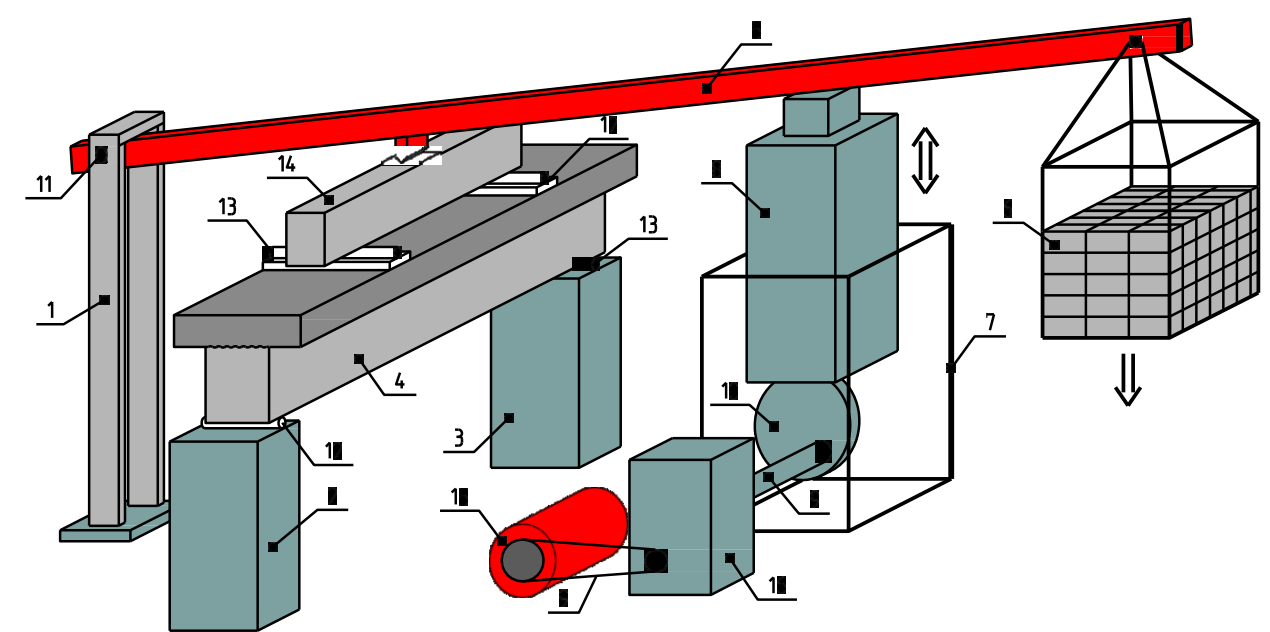

1 - frame; 2, 3 - supports; 4 - experimental beam; 5 - lever; 6 - load; 7 - guides; 8 - pusher; 9 - drive; 10 - eccentric; 11 - hinge; 12 - movable support; 13 - fixed support; 14 - traverse; 15 - electric motor; 16 - worm gear.

Fig. 3. Experimental plant for testing composite RC beams under cyclic loads

The displacement of the in-situ concrete layer relative to the prefabricated part of the section at the contact level, as well as the opening of a horizontal crack along the contact, was fixed in the area bounded by inclined cracks above the separate outlined compressed 
concrete strut. The data is presented in Figures 3, 4 (graphs are presented for the support areas in which the collapse occurred).

As can be seen from the graphs shown in Fig. 5 and 6, three stages can be distinguished during the development of contact deformations: the first is characterized by a sudden jump in the development of damage and the same rapid damping, passing into an almost linear second stage.

Table 3. Main results of experimental studies of beam samples under cyclic loading

\begin{tabular}{|c|c|c|c|c|c|}
\hline Specimens & $\begin{array}{l}\text { Loading level } \\
\text { from static } \\
\text { ultimate load, \% }\end{array}$ & $\begin{array}{c}\text { Number of } \\
\text { cycles } \\
\text { before } \\
\text { failure }\end{array}$ & $\begin{array}{c}\text { Maximum } \\
\text { contact crack } \\
\text { opening, mm }\end{array}$ & $\begin{array}{l}\text { Maximum } \\
\text { contact } \\
\text { slip, mm }\end{array}$ & $\begin{array}{l}\text { Maximum } \\
\text { deflection in the } \\
\text { middle of the } \\
\text { span, mm }\end{array}$ \\
\hline B2 & 0,9 & 256 & 1,238 & 0,607 & 9,523 \\
\hline B3 & 0,62 & 37740 & 0,707 & 0,241 & 6,733 \\
\hline B4 & 0,62 & 23150 & Not measured & 0,375 & 7,055 \\
\hline \multicolumn{6}{|c|}{$\begin{array}{l}\text { Note: the slip was fixed approximately in the middle of the horizontal area of the contact } \\
\text { disintegration between the inclined cracks. The maximum value is presented for the moment } \\
\text { preceding the fracture. }\end{array}$} \\
\hline
\end{tabular}

The second stage covers most of the "viability" (up to $70 \%$ of the total test duration) of the prototype and is characterized by a low increase in deformations. The third stage is described by a sudden jump-like deformation of the contact, ending in the physical destruction of the construction.

a)

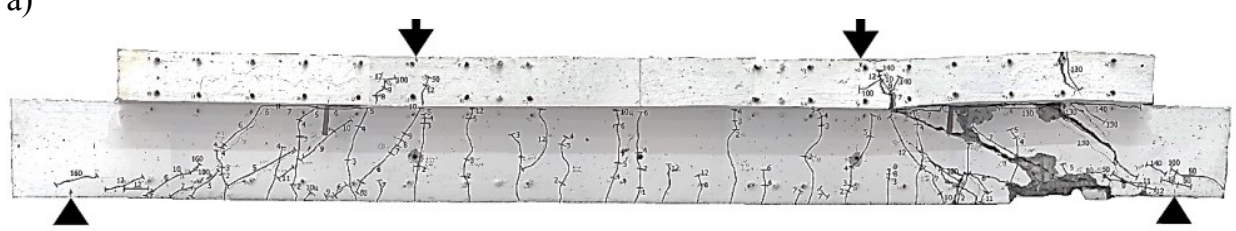

b)

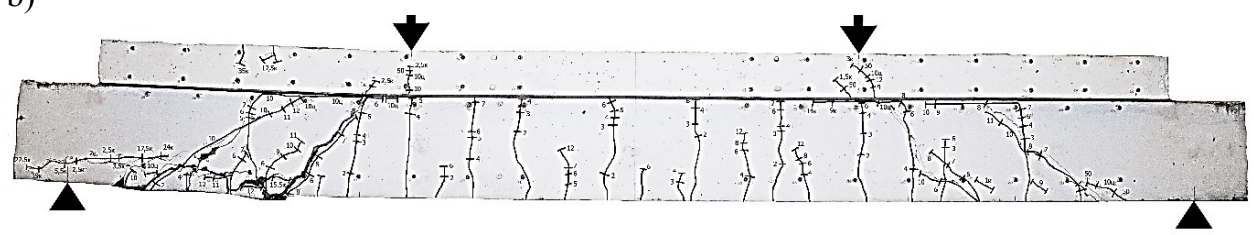

c)

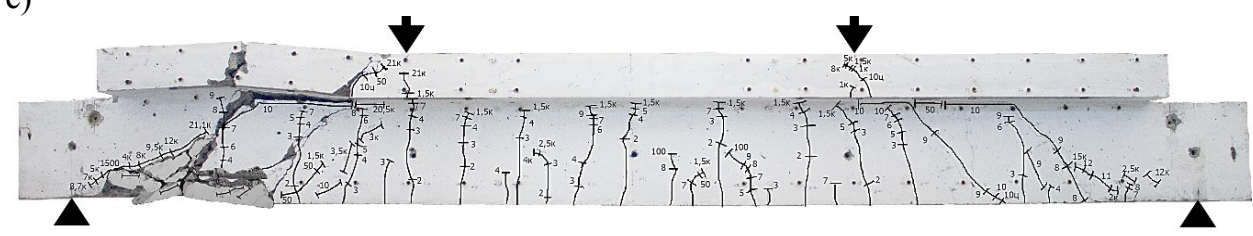

a) beam B2; b) beam B3; c) beam B4

Fig. 4. The crack pattern and fracture pattern of experimental beams under cyclic load application.

As in the experiment cyclic tests of beam elements were started after the formation of the initial crack in the contact of monolithic and prefabricated parts (at the stage of static loading of the beam to the required level), and the effect of chemical adhesion in contact is practically absent, then basically there will be two mechanisms of the shear transfer along the crack: the effect of engagement of concrete aggregates (or the friction effect) and the 
nagel effect due to bending of transverse bas along the contact surface. Due to the fact that shear displacements develop along the crack plane, the protruding along the contact particles increase the crack opening width (dilatancy effect).
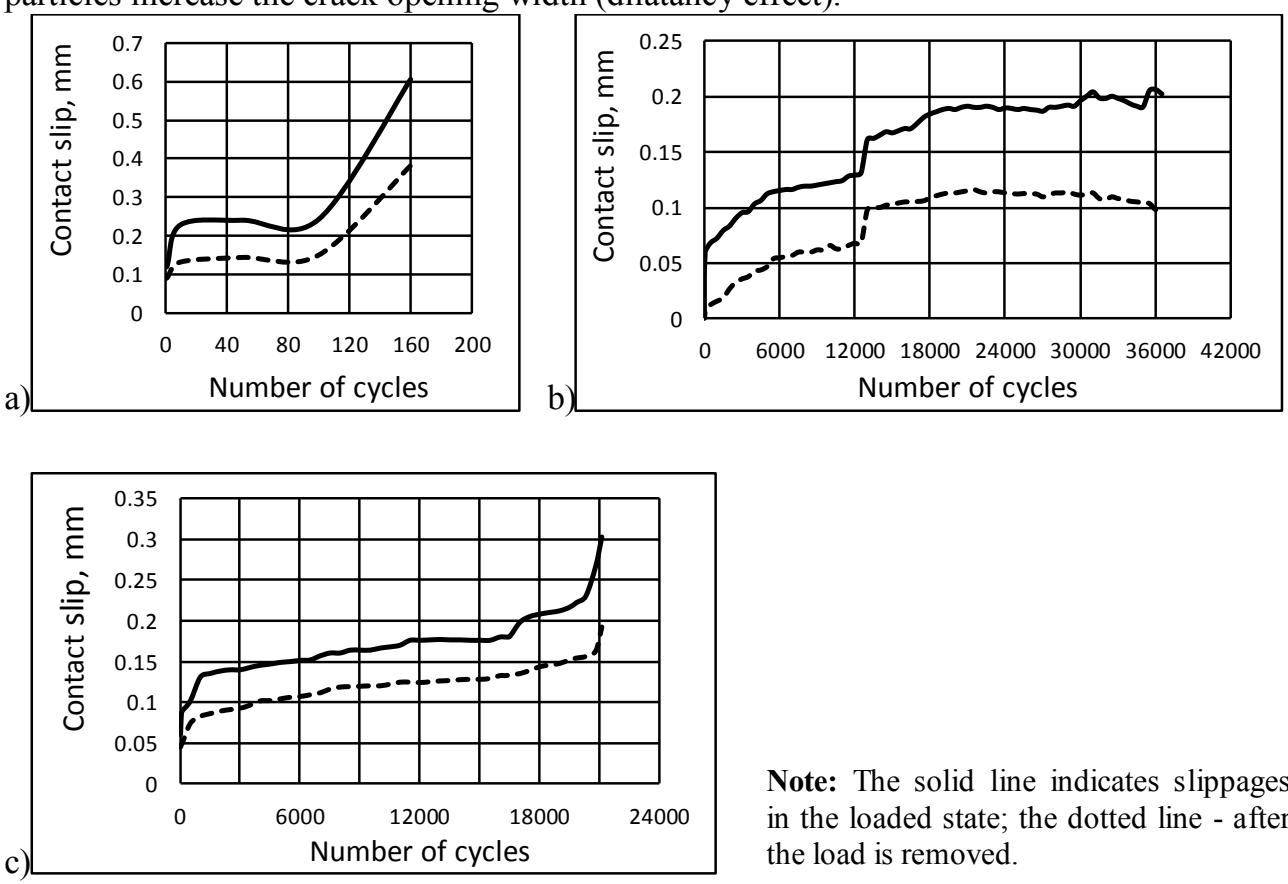

Note: The solid line indicates slippages in the loaded state; the dotted line - after the load is removed.

a) beam B2; b) beam B3; c) beam B4

Fig. 5. Graphs of the development of the slip along the contact of the monolithic part relative to the prefabricated one, depending on the number of loading cycles
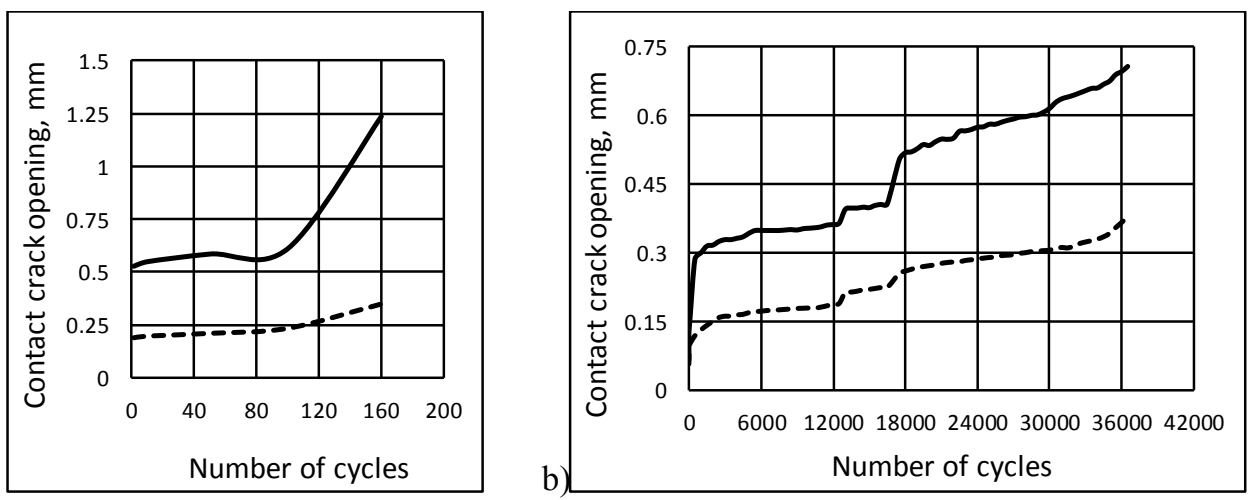

Note: The solid line indicates slippages in the loaded state; the dotted line - after the load is removed. a) beam B2; b) beam B3

Fig. 6. Graphs of the change in the width of the horizontal crack opening along the contact of the monolithic and prefabricated parts, depending on the number of loading cycles.

The crack opening increases the axial stress of the bars, while the slip displacement causes a bending effect in them. Thus, the complete stress state in contact, namely the work of the transverse bars and the concrete surrounding them, is regulated by the crack opening along the contact and slip displacement. 
Analyzing national regulations [5], as well as a number of European countries [6,7] and the USA [8], one can conclude the following:

1) The European standards Eurocode 2 [6] (as well as the current in the Belarus TCP EN 1992-1-1 [5]) fail to take proper care to the operation of contact joints of composite cross-sections in structures under static loads. With cyclical or repeated impacts, the issue is practically not worked out. On the pages of EN 1992-1-1 [6], one can find the only relationship for calculating the limiting shear stresses along the contact, which, under cyclic loads, is modified only by halving one of the coefficients depending on the roughness of the contact surface.

2) The Earthquake Planning and Protection Organization of Greece in 2012 gave effect to the final version of the national standard on impacts on structures during earthquakes "Greek Code of Structural Interventions 2012" (GCSI 2012 [7]). This document discusses in detail the issue of designing the contact zone of old and new concrete under dynamic influences in accordance with the provisions of the theory of reliability.

It's worth to remark that the slip along the contact is directly correlated with the corresponding crack opening and affects the level of damage to the reinforced element. For this reason, the contact slip is a critical parameter that must be evaluated when finding criteria for possible damage to the strengthened element, in particular when concrete in-situ strengthening layer is constructed.

According to the Greek standard [7], the acceptable value of relative slip displacements in contact depends on the target level of responsibility of the structure. Thus, the maximum acceptable value of the slip displacement for level A (associated with the limitation of the level of damage) is $0.2 \mathrm{~mm}$, for level B (associated with the level of life safety or with the level of limitation of significant damage) is $0.8 \mathrm{~mm}$ and for level $\mathrm{C}$ (associated with the level of limitation of failure or with the level of a condition close to failure) is $1.5 \mathrm{~mm}$. It should be noted that the tests of the beams carried out at a loading level of $0.62 \mathrm{Fu}$ showed that at the stage preceding the collapse, the width of the horizontal crack did not exceed 1 $\mathrm{mm}$.

As an alternative to the Greek GCSI 2012 [7], one can refer to the North American FEMA $356 / 2000$ standards [8], in which the maximum value of the crack opening width along the contact should not exceed $1.6 \mathrm{~mm}$ and $3.2 \mathrm{~mm}$ for the stage of serviceability and life safety, respectively.

\section{Conclusion}

Based on the above, the following conclusions can be drawn:

1. The carried-out studies allowed to define the failure pattern of composite RC beam elements under cyclic loading.

2. With a decrease in the level of applied load, with its frequency unchanged, the "viability" of the experimental construction increased (the number of cycles before collapse);

3. Under cyclic effects, shear deformations and contact openings are characterised by nonlinear functions;

4. With an increase in the number of loading cycles, the rigidity of the beam sample decreases;

5. With cyclic loads of $0.9 \mathrm{Fu}$ and $0.62 \mathrm{Fu}$, the maximum fixed deflection in the middle of the span of the experimental beams is $12 \%$ and $35 \%$ less, respectively, than during static tests. 


\section{References}

1. O. Tsioulou, S. Dritsos A Theoretical Model to Predict Interface Slip due to Bending, RILEM - Materials and Structures, 4, (2011)

2. V. Palieraki, E. Vintzileou, K. Trezos Shear Transfer Along Interfaces: Constitutive Laws, Proceedings of the 2nd European Conference on Earthquake Engineering and Seismology, Istanbul, Turkey (2014)

3. Mirsayapov Il.T. New methods for calculating reinforced concrete structures for durability under the combined action of bending moments and transverse forces, Scientific proceedings of the III All-Russian (II International) Conference on Concrete and reinforced concrete "Concrete and reinforced concrete - a look into the future" 1, Moscow, Russia (2014)

4. A. R. Moradi, M. Soltani, and A. A. Tasnimi, A simplified constitutive model for dowel action across RC cracks, Journal of Advanced Concrete Technology, 10 (2012).

5. Technical code of common practice TCP EN 1992-1-1-2009 (02250). Eurocode 2: Design of concrete structures - Part 1-1: General rules and rules for buildings. 01.01.2010. - Minsk: Ministry of Architecture and Architecture of the Republic of Belarus (2010)

6. EN 1992-1-1 Eurocode 2: Design of concrete structures - Part 1-1: General rules and rules for buildings. - Brussels: CEN (2004)

7. E.P.P.O. Code for Structural Interventions, Earthquake Planning and Protection Organization of Greece (Ep.P.P.O.). Athens (2012)

8. FEMA 356: prestandard and commentary for the seismic rehabilitation of buildings American society of civil engineers. Federal Emergency Management Agency, Washington (2000) 